Case Report

\title{
Ultrasound Confirmation of the Multiple Loci Hypothesis of the Myofascial Trigger Point and the Diagnostic Importance of Specificity in the Elicitation of the Local Twitch Response
}

\author{
Andrew Ball 1,2,3,*, Thomas Perreault ${ }^{2,4}$ (D), César Fernández-de-las-Peñas ${ }^{5, *(\mathbb{D})}$, Michael Agnone ${ }^{1}$ (D) \\ and Jordan Spennato ${ }^{1}$ \\ 1 Atrium Health, Carolinas Rehabilitation, Charlotte, NC 28211, USA; \\ Michael.Agnone@atriumhealth.org (M.A.); Jordan.Spennato@atriumhealth.org (J.S.) \\ 2 Myopain Seminars, 4405 East-West Highway, Suite 401, Bethesda, MD 20814, USA; \\ Thomas.Perreault@WDHospital.org \\ 3 NxtGen Institute, 2138 Scenic Highway, Snellville, GA 30078, USA \\ 4 Wentworth-Douglass Hospital Rehab Services at Dover, 789 Central Avenue, Dover, NH 03820, USA \\ 5 Department of Physical Therapy, Occupational Therapy, Rehabilitation and Physical Medicine, \\ Universidad Rey Juan Carlos, 28922 Madrid, Spain \\ * Correspondence: Andrew.Ball@atriumhealth.org (A.B.); cesar.fernandez@urjc.es (C.F.-d.-1.-P.)
}

\section{check for} updates

Citation: Ball, A.; Perreault, T.;

Fernández-de-las-Peñas, C.; Agnone, M.; Spennato, J. Ultrasound Confirmation of the Multiple Loci Hypothesis of the Myofascial Trigger Point and the Diagnostic Importance of Specificity in the Elicitation of the Local Twitch Response. Diagnostics 2022, 12, 321. https://doi.org/ 10.3390/diagnostics12020321

Academic Editor: Chao-Min Cheng

Received: 4 January 2022

Accepted: 25 January 2022

Published: 27 January 2022

Publisher's Note: MDPI stays neutral with regard to jurisdictional claims in published maps and institutional affiliations.

Copyright: (C) 2022 by the authors. Licensee MDPI, Basel, Switzerland. This article is an open access article distributed under the terms and conditions of the Creative Commons Attribution (CC BY) license (https:// creativecommons.org/licenses/by/ $4.0 /)$.

\begin{abstract}
The literature has hypothesized that a trigger point $(\operatorname{Tr} \mathrm{P})$ area consists of a hyperperfused contracture knot with smaller hypoperfused TrPs within the contracture knot. By contrast, the only published ultrasound image of a $\mathrm{TrP}$ has it labeled hypoechoic (i.e., hyperperfused) with no commentary regarding smaller speckles of hypoperfusion within. Furthermore, the lack of clarity in objective definition of the terms associated with the $\operatorname{TrP}$ (namely, the palpable "contracture knot" and smaller nonpalpable "trigger point") has led to unnecessary communication difficulties between and among clinicians and researchers. In this case series of three muscles across two patients, by using high-definition musculoskeletal ultrasound imaging technology, we present what we believe to be the first reliable capture of palpable hypoechoic (e.g., hypoperfused) contracture knots (previously mislabeled as a hypoechoic $\operatorname{Tr} \mathrm{P}$ ), and a visual support of the multiple loci hypothesis first proposed by Hong and Simons - the first reliable confirmation of the hyperechoic (i.e., hypoperfused) $\operatorname{Tr} P$ within. Initially proposed by a histological study and supported by microdialysis study, this case series lends further support for the multiple loci hypothesis through visual confirmation of palpable hypoechoic contracture knots, with smaller hypoechoic TrPs "speckles" within.
\end{abstract}

Keywords: ultrasound; trigger point; dry needling; injection; case series

\section{Introduction}

Characterized as a motor and/or sensory disorder, or myofascial trigger point $(\mathrm{TrP})$ that refers pain [1], myofascial pain syndrome is estimated to affect from $30 \%$ to $85 \%$ of the population [2]. The integrated hypothesis of $\operatorname{TrP}$ formation is the most widely accepted model describing TrP formation in the skeletal muscle. It involves a cascade of events including the leakage of acetylcholine into the synaptic cleft and the release of calcium into the sarcoplasmic reticulum, resulting in a nonvolitional muscle contraction at the motor endplate [3]. Considering the theoretically small size of the TrP, some authors have questioned if TrPs can be palpated with accuracy $[4,5]$.

Clinicians use manual palpation to identify TrPs, with "spot tenderness" and "referred pain" among the most common features for TrP identification [6,7]. However, recent research indicates the reliability of manual palpation is questionable and has poor reproducibility for eliciting TrP-related symptoms [8]. For example, needling of TrPs was shown to produce referred pain and local twitch responses (LTR) when prior manual palpation failed to do so $[9,10]$. It has been traditionally accepted that maximal target specificity of the 
dry needling technique is advisable when an LTR is the procedural goal [11]. Nevertheless, it has been recently observed that, although the LTR elicited during dry needling can be clinically relevant, clinical outcomes on pain and function are not directly related just to the fact of eliciting LTR $[12,13]$. Accordingly, the therapeutic value of the LTR is a current hotly debated topic in the literature [14].

A dual-action effect of dry needling integrating updated pain neuroscience mechanisms is currently hypothesized [15]: a first local biomechanical effect mitigated by needle manipulation of collagen fibers, and a second neurological/sensory effect of more theoretical importance in centrally sensitized patients [15]. The literature to date has not delineated patients with and without central sensitization in a study of the clinical value of the LTR [13]. Nevertheless, clinicians performing TrP injection (TrP-I) or TrP dry needling (TrP-DN) hold to empirical evidence that for optimal clinical results, specificity wherein the needle contacts the precise target is paramount. However, the specificity of targeting the $\operatorname{Tr} \mathrm{P}$ area during dry needling procedure has been recently questioned when applying this intervention in individuals with stroke [16].

Two microdialysis studies revealed ischemia and hypoxia within $\operatorname{TrP}$ areas with surrounding hyperperfusion $[17,18]$. Proper understanding of ultrasound imaging (US) suggests that, in general, hyperperfused structures appear as hypoechoic (dark grey) and hypoperfused structures as hyperechoic (light grey) [19]. Previous US studies had instead identified and labeled TrPs as hypoechoic (dark grey) [20,21]. A hypoechoic $\operatorname{TrP}$ image suggests either anisotropy (image error) or, in direct contrast to widely accepted microdialysis literature $[17,18]$, that the $\operatorname{TrP}$ is a hyperperfusion area.

Over the years, the terms "contracture knot" and "TrP" have been used interchangeably [22,23]. This lack of clarity in objective definition of these two terms has led to unnecessary communication difficulties among clinicians and researchers. Hong proposed that the sensorimotor abnormalities of TrPs are related to multiple sensitized afferent nerves [24] and motor endplates [25] contained within the "TrP region," or what clinicians define as a palpable "contracture knot". Meng et al. identified an increased number of afferent nerve fibers in the "TrP region" compared to normal muscle tissue and concluded that proliferation of afferent nerve fibers plays a significant role in TrP pathophysiology [26]. Recent studies on animal models support the idea that contracture knots are collections of smaller TrPs located at the neuromuscular junctions [27], but this phenomenon has not been visualized to date with US. An old previous attempt at US of TrPs failed to reliably identify contracture knots due to limitations in the imaging technology at the time of the study [28]. In the following years, advancements in the technology of the ultrasound probe and computerized imaging processing have resulted in dramatic advancements in image quality [29,30]. In fact, a recent study used US imaging for assessing the intensity of the LTR during the application of dry needling [31]; however, this study failed to visualize the TrP area itself under US.

We present here two patients in whom we were able to capture the contracture knots, by using high-definition US technology, representing the first visual confirmation of Hong's multiple loci hypothesis [24]. Accordingly, we describe three muscles across two single patients, where we visualized that the palpable and hyperperfused contracture knot is actually a collection of much smaller nonpalpable hypoperfused TrPs at motor endplates residing within the palpable contracture knot.

\section{Case Report \#1}

The first case was a $6^{\prime} 2^{\prime \prime}, 185$ lbs., 53-year-old male subject (previously evaluated by both primary care physician and doctor of physical therapy to rule out other causes of symptoms other than myofascial TrPs) with dual complaints of intermittent right plantar foot and right shoulder pain previously successfully treated by $\operatorname{TrP}$ dry needling of the gastrocnemius and deltoid, respectively.

A taut band with a palpable nodule within the medial gastrocnemius was identified as responsible for his right plantar heel pain symptoms [32]. As had been the case with 
previous bouts of plantar pain, the subject reported, upon palpation, a pain referral symptomatology into the plantar aspect of his foot as his pain symptoms (pain recognition). The nodule was subsequently imaged in long-axis with a Siemens Acuson S200 Ultrasound system (Siemens, Munich, Germany) with an 18L6 $16 \mathrm{~Hz}$ high-definition linear probe. A large hypoechoic contracture knot $(109 \mathrm{~mm} \times 47 \mathrm{~mm}$ ) was identified (Figure 1 ) with smaller hyperechoic "speckles" (Figure 2) within the hypoechoic contracture knot.

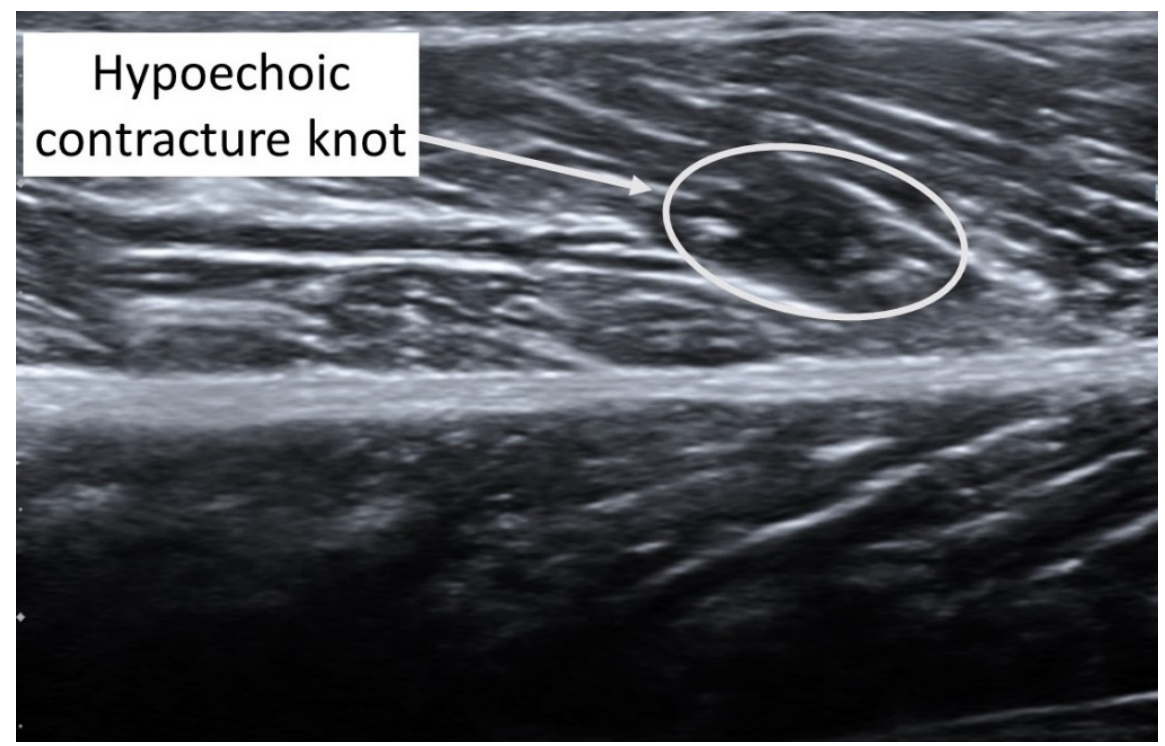

Figure 1. Ultrasound imaging assessment of the right gastrocnemius muscle showing the palpable contracture knot as a hypoechoic (hyperperfused) area.

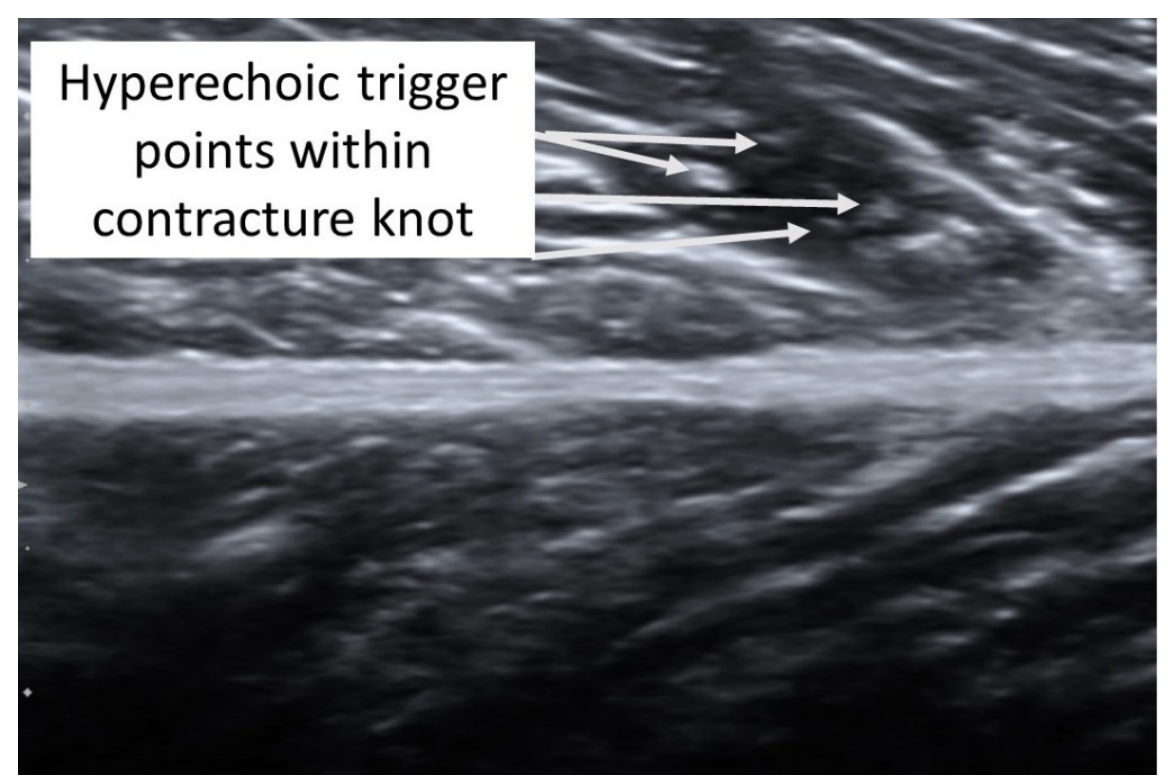

Figure 2. Detailed ultrasound imaging assessment of the right gastrocnemius muscle showing a collection of small hyperechoic (hypoperfused) "TrP speckles" within the contracture knot.

In addition, taut bands with palpable nodules responsible for his right shoulder pain were also identified in the right anterior and middle deltoid muscles. As had been the case with previous bouts of shoulder complaints, the subject reported, upon palpation, a referred pain symptom spreading down the anterior and middle aspect of his upper extremity. The spots were subsequently imaged in short-axis with a Siemens Acuson S200 Ultrasound system with an 18L6 $16 \mathrm{~Hz}$ high-definition linear probe. Two large hypoechoic contracture 
knots (Figure 3) (both $\sim 75 \mathrm{~mm} \times \sim 75 \mathrm{~mm}$ ) were identified with smaller hyperechoic "speckles" (Figure 4) within each hypoechoic contracture knot.

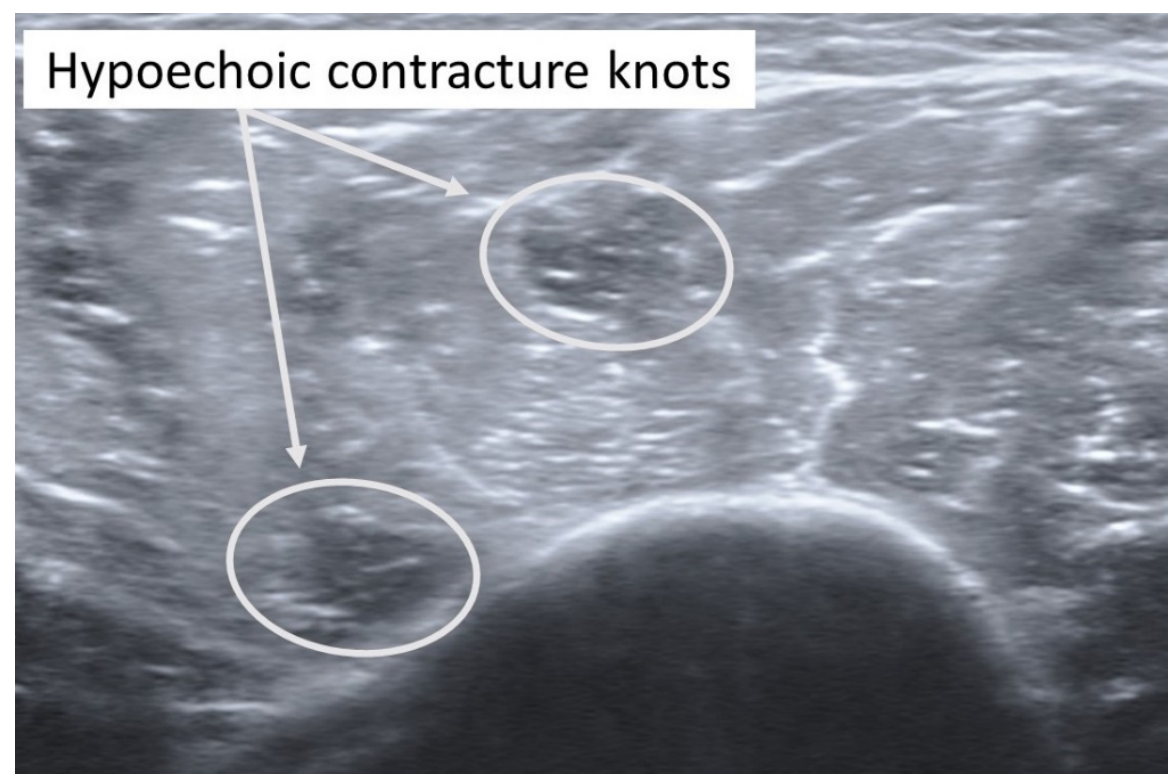

Figure 3. Ultrasound imaging assessment of the right deltoid muscle showing two palpable contracture knots as hypoechoic (hyperperfused) areas.



Figure 4. Detailed ultrasound imaging assessment of the right deltoid muscle showing a collection of small hyperechoic (hypoperfused) "TrP speckles" within each of the contracture knots.

\section{Case Report \#2}

The second case was a 5'6", 130 lbs., 26-year-old female subject (previously evaluated by both primary care physician and doctor of physical therapy to rule out other causes of symptoms other than TrPs) with left temporal headaches previously successfully treated by TrP-DN of the left upper trapezius. A taut band with palpable nodule within the left upper trapezius muscle was identified. As had been the case with previous headaches, the subject reported, upon palpation, pain referral symptoms spreading up the neck, around the ear, and into the temple [32]. The nodule was subsequently imaged in long-axis with a General Electric Voluson i Ultrasound System with a 12L-SC $13 \mathrm{MHz}$ linear probe. A large hypoechoic contracture knot $(61 \mathrm{~mm} \times 22 \mathrm{~mm}$ ) was identified (Figure 5) with smaller 
hyperechoic "speckles" (Figure 6) within the hypoechoic contracture knot (approximately $1 \mathrm{~mm} \times 1 \mathrm{~mm}$ ).

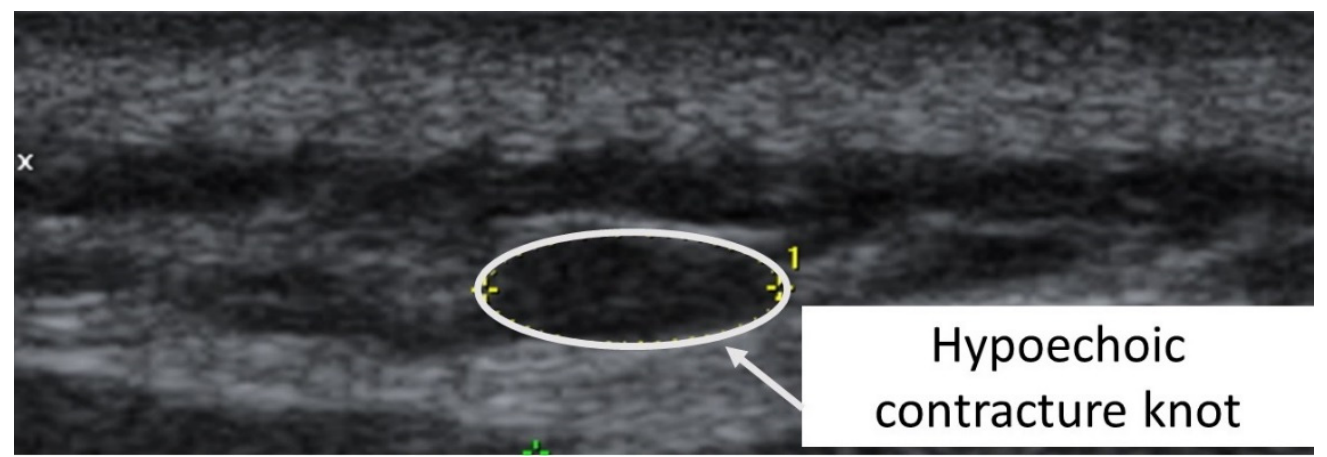

Figure 5. Ultrasound imaging assessment of the left upper trapezius muscle showing a palpable contracture knot as a hypoechoic (hyperperfused) area.

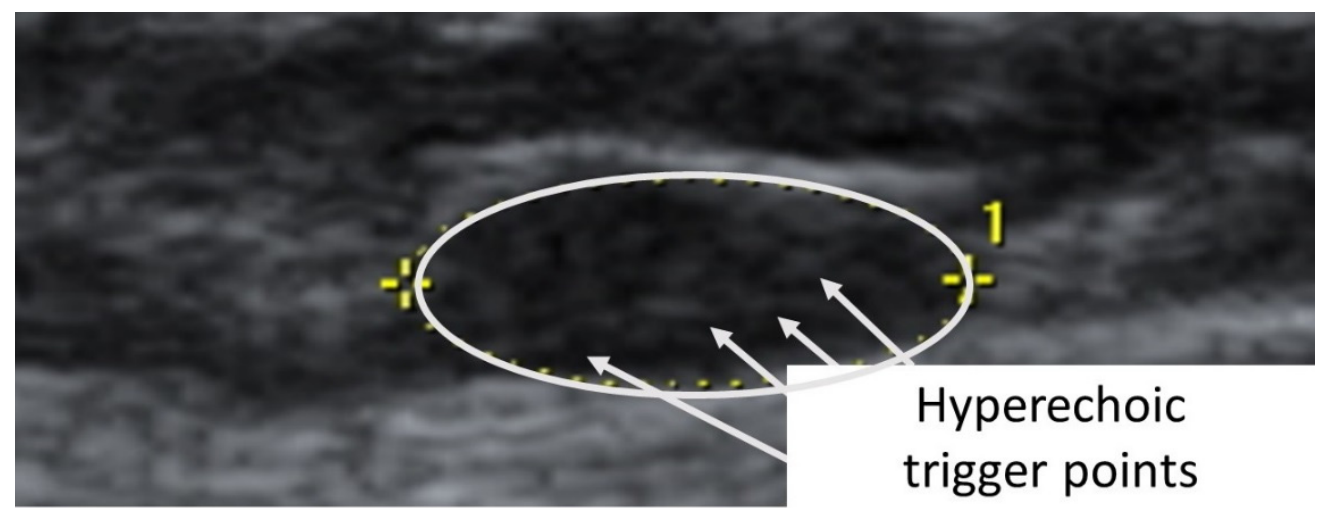

Figure 6. Detailed ultrasound imaging assessment of the left upper trapezius muscle showing a collection of small hyperechoic (hypoperfused) "TrP speckles" within the contracture knot.

\section{Discussion}

Considering that the pathogenesis of TrPs consists of dysfunctional motor endplates and they are ischemic areas in nature, previous studies may have mislabeled contracture knots as TrPs [19]. In each case presented, a hypoechoic/hyperperfused area of approximately $1 \mathrm{~cm} \times 1 \mathrm{~cm}$ was visualized in the vicinity of the palpable nodule, with small hyperechoic/nonpalpable speckles of approximately $1 \mathrm{~mm} \times 1 \mathrm{~mm}$ within each. Consistent with the multiple loci hypothesis presented by Hong and Simons [25], we suggest that the relatively large hypoechoic structures visualized as the $\mathrm{TrP}$ area in both subjects examined represent hyperperfused contracture knots with smaller, not previously distinguished, ischemic and hyperechoic TrPs within each.

The visual confirmation of contracture knots in the muscle being hyperperfused challenges the idea that the therapeutic benefit of dry needling is related to a "wash out effect" that somehow results in reperfusion of what we now suggest is an already hyperperfused region [20,21]. We propose a new hypothesis suggesting that when performing TrP-DN, an initial therapeutic effect may occur due to decreasing (not increasing) perfusion of hyperperfused contracture knot relative to the surrounding skeletal muscle. In addition, elicitation of a more specific perfusion-homeostatic effect likely occurs upon needle stimulation of the smaller hyperechoic (e.g., hypoperfused) TrPs within the contracture knot. Consistent with the multiple loci hypothesis (Figure 7), it is conceivable that the needle tip also pricks the afferent nerve endings that are sensitized within and around the hypoperfused TrPs to elicit analgesic effects [33]. It is possible that the mechanisms underlying TrPs are much more complex than previously realized. 


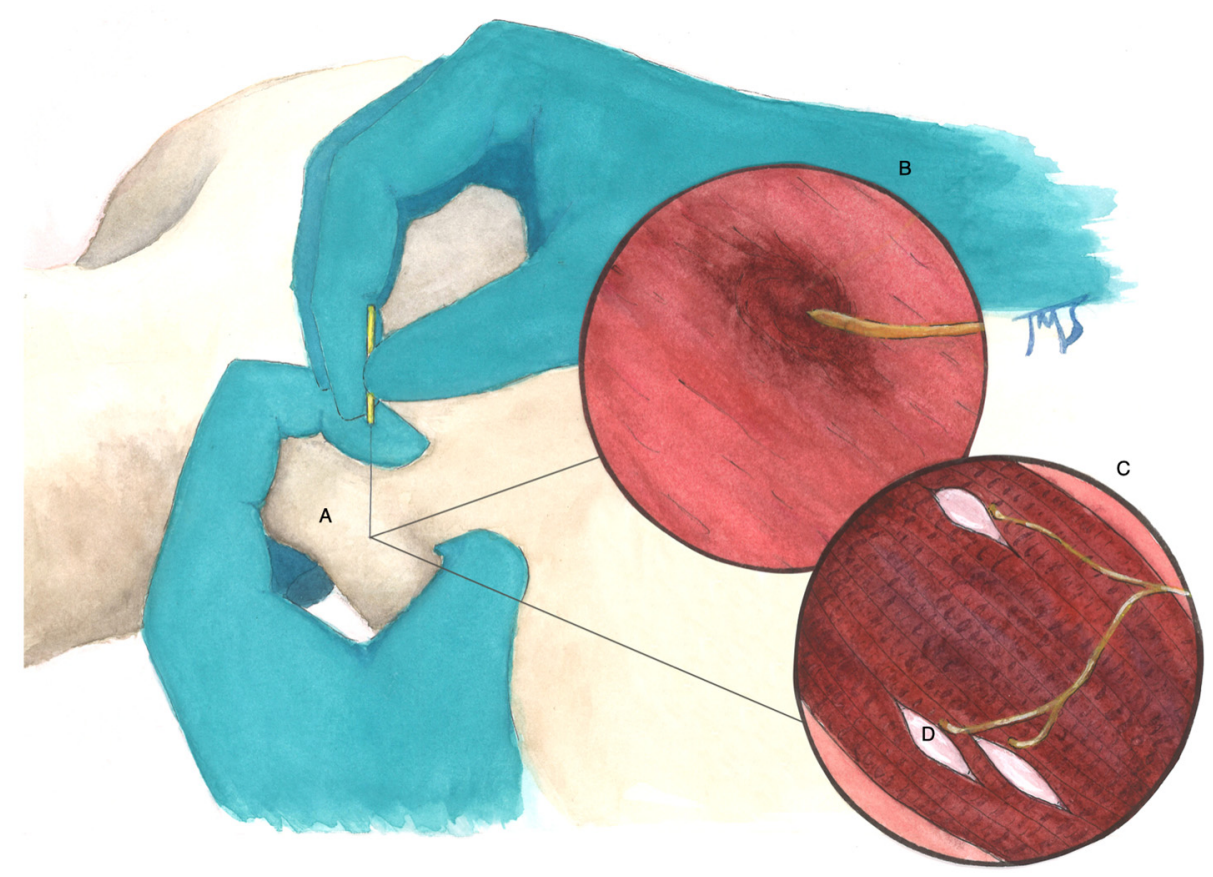

Figure 7. Illustration of the multiple loci hypothesis. (A) Palpable, tender nodule located within a taut band of skeletal muscle; (B) hyperperfused, hypoechoic contracture knot and nearby motor nerve; (C) multiple hypoperfused and hyperechoic trigger points located within a contracture knot; (D) region of multiple active loci (motor end plates) and sensitive loci (sensitized afferent nerve endings).

\subsection{Limitations}

Although hypoechoic images are generally considered hyperperfused and hyperechoic images are generally considered hypoperfused [19], the possibility of image artifact (anisotropy) in our patients cannot be ruled out. For example, acoustic shadow behind calcification, lymph nodes, and some select pathological conditions may present as hypoechoic areas. Furthermore, small, curved, superficially located musculoskeletal structures (such as tendon and joint structures) and deep muscular structures requiring the use of a lowfrequency, low-definition curvilinear probe are particularly susceptible to anisotropy [34]. We believe that in the cases presented, the probability of anisotropy is quite low secondary to the use of a high-frequency linear probe to examine superficial structures. Anisotropy would represent theoretical incongruence with both current understanding of the biochemical milieu of the contracture knot and $\operatorname{TrP}[17,18]$, and the multiple loci hypothesis [24].

\subsection{Clinical Relevance}

Currently, the therapeutic value of eliciting an LTR during dry needling is a matter of professional opinion [14]. However, the evaluative ability for "needle palpation" to elicit an LTR as an objective sign of $\operatorname{TrP}$ presence is less debatable [11,13,33]. We propose, based on current data, that the LTR is not necessarily elicited by needle stimulation of the contracture knot, but it is elicited by needle stimulation of smaller TrPs within the contracture knot-as previously theorized $[11,13,33,35,36]$ and for the first time visualized and identified-in the cases presented.

Additionally, the visual confirmation of contracture knots in a muscle being hyperperfused challenges the idea of dry needling deriving part of its therapeutic benefit via a "wash out effect" that somehow results in reperfusion [37] of what we now suggest is an already hyperperfused region. Since this is just a case series including two cases, visual confirmation of the multiple loci hypothesis is a necessary consideration toward accurate structure identification and labeling for professional communication, research, education, and procedural target specificity of dry needling interventions. 


\section{Conclusions}

In clinical procedures such as TrP-DN where a LTR is preferable obtained, optimization of target specificity is key. Initially supported by a histological study [17,38], this case series lends further support for the multiple loci hypothesis through visual confirmation of palpable contracture knots with smaller TrPs within.

Author Contributions: Conceptualization, A.B. and T.P.; methodology: A.B.; analysis: A.B. and T.P.; investigation: A.B.; resources A.B.; image curation: A.B.; writing-original draft preparation: A.B., T.P., C.F.-d.-1.-P., M.A. and J.S.; writing-review and editing: A.B., T.P., C.F.-d.-1.-P., M.A. and J.S.; graphic art: J.S. All authors have read and agreed to the published version of the manuscript.

Funding: This research received no external funding.

Institutional Review Board Statement: The study was conducted according to the guidelines of the Declaration of Helsinki. The Atrium Health IRB has reviewed and determined study 07-21-27EX meets the criteria for exempt status set forth in Code of Federal Regulations Title 45 CFR 46.104, Category 2. The atrium IRB acknowledges the De-Identification Checklist affirming compliance with guidelines that protect confidentiality by recording information in a manner that does not allow subjects to be identified directly or through identifiers linked to subjects-7/21/2021.

Informed Consent Statement: Informed consent was obtained from all subjects included in the study.

Data Availability Statement: Not applicable.

Acknowledgments: The authors would like to thank Cress Goodnight, PT and Novant Health for the generous gift of time and access to their ultrasound imaging equipment.

Conflicts of Interest: The authors declare no conflict of interest.

\section{References}

1. Gerwin, R.D. Classification, epidemiology, and natural history of myofascial pain syndrome. Curr. Pain Headache Rep. 2001, 5, 412-420. [CrossRef] [PubMed]

2. Vazquez-Delgado, E.; Cascos-Romero, J.; Gay-Escoda, C. Myofascial pain syndrome associated with trigger points: A literature review. (I): Epidemiology, clinical treatment and etiopathogeny. Med. Oral Patol. Oral Cir. Bucal 2009, 14, e494-e498. [CrossRef] [PubMed]

3. Gerwin, R.D.; Dommerholt, J.; Shah, J.P. An expansion of Simons' integrated hypothesis of trigger point formation. Curr. Pain Headache Rep. 2004, 8, 468-475. [CrossRef] [PubMed]

4. Lucas, N.; Macaskill, P.; Irwig, L.; Moran, R.; Bogduk, N. Reliability of physical examination for diagnosis of myofascial trigger points: A systematic review of the literature. Clin. J. Pain 2009, 25, 80-89. [CrossRef] [PubMed]

5. Lew, P.C.; Lewis, J.; Story, I. Inter-therapist reliability in locating latent myofascial trigger points using palpation. Man. Ther. 1997, 2, 87-90. [CrossRef]

6. Li, L.; Stoop, R.; Clijsen, R.; Hohenauer, E.; Fernández-de-Las-Peñas, C.; Huang, Q.; Barbero, M. Criteria Used for the Diagnosis of Myofascial Trigger Points in Clinical Trials on Physical Therapy: Updated Systematic Review. Clin. J. Pain 2020, 36, $955-967$. [CrossRef]

7. Fernández-de-Las-Peñas, C.; Dommerholt, J. International consensus on diagnostic criteria and clinical considerations of myofascial trigger points: A Delphi study. Pain Med. 2018, 19, 142-150. [CrossRef]

8. Rathbone, A.T.; Grosman-Rimon, L.; Kumbhare, D.A. Interrater agreement of manual palpation for identification of myofascial trigger points. Clin. J. Pain 2017, 33, 715-729. [CrossRef]

9. Hong, C.-Z.; Kuan, T.-S.; Chen, J.-T.; Chen, S.-M. Referred pain elicited by palpation and by needling of myofascial trigger points: A comparison. Arch. Phys. Med. Rehabil. 1997, 78, 957-960. [CrossRef]

10. Poveda-Pagan, E.J.; Lozano-Quijada, C.; Segura-Heras, J.V.; Peral-Berna, M.; Lumbreras, B. Referred Pain Patterns of the Infraspinatus Muscle Elicited by Deep Dry Needling and Manual Palpation. J. Altern. Complement. Med. 2017, 23, 890-896. [CrossRef]

11. Hong, C.Z. Lidocaine injection versus dry needling to myofascial trigger point. The importance of the local twitch response. Am. J. Phys. Med. Rehabil. 1994, 73, 256-263. [CrossRef] [PubMed]

12. Koppenhaver, S.L.; Walker, M.J.; Rettig, C.; Davis, J.; Nelson, C.; Su, J.; Fernández-de-Las-Peñas, C.; Hebert, J.J. The association between dry needling-induced twitch response and change in pain and muscle function in patients with low back pain: A quasi-experimental study. Physiotherapy 2017, 103, 131-137. [CrossRef] [PubMed]

13. Fernández-de-las-Peñas, C.; Plaza-Manzano, G.; Sánchez-Infante, J.; Gómez-Chiguano, G.F.; Cleland, J.A.; Arias-Buría, J.L.; Navarro-Santana, M.J. The importance of the local twitch response during needling interventions in spinal pain associated to myofascial trigger points: A systematic review and meta-analysis. Acupunct. Med. 2021, in press. [CrossRef] [PubMed] 
14. Perreault, T.; Dunning, J.; Butts, R. The local twitch response during trigger point dry needling: Is it necessary for successful outcomes? J. Bodyw. Mov. Ther. 2017, 21, 940-947. [CrossRef]

15. Fernandez-de-Las-Penas, C.; Nijs, J. Trigger point dry needling for the treatment of myofascial pain syndrome: Current perspectives within a pain neuroscience paradigm. J. Pain Res. 2019, 12, 1899-1911. [CrossRef] [PubMed]

16. Hernandez-Ortiz, A.R.; Ponce-Luceno, R.; Saez-Sanchez, C.; Garcia-Sanchez, O.; Fernandez-de-Las-Penas, C.; de-la-Llave-Rincon, A.I. Changes in Muscle Tone, Function, and Pain in the Chronic Hemiparetic Shoulder after Dry Needling Within or Outside Trigger Points in Stroke Patients: A Crossover Randomized Clinical Trial. Pain Med. 2020, 21, 2939-2947. [CrossRef]

17. Sikdar, S.; Ortiz, R.; Gebreab, T.; Gerber, L.H.; Shah, J.P. Understanding the vascular environment of myofascial trigger points using ultrasonic imaging and computational modeling. Annu. Int. Conf. IEEE Eng. Med. Biol. 2010, 2010, 5302-5305. [CrossRef]

18. Shah, J.P.; Danoff, J.V.; Desai, M.J.; Parikh, S.; Nakamura, L.Y.; Phillips, T.M.; Gerber, L.H. Biochemicals associated with pain and inflammation are elevated in sites near to and remote from active myofascial trigger points. Arch. Phys. Med. Rehabil. 2008, 89, 16-23. [CrossRef]

19. Ihnatsenka, B.; Boezaart, A.P. Ultrasound: Basic understanding and learning the language. Int. J. Shoulder Surg. 2010, 4, 55-62. [CrossRef]

20. Mazza, D.F.; Boutin, R.D.; Chaudhari, A.J. Assessment of Myofascial Trigger Points via Imaging: A Systematic Review. Am. J Phys. Med. Rehabil. 2021, 100, 1003-1014. [CrossRef]

21. Duarte, F.C.K.; West, D.W.D.; Linde, L.D.; Hassan, S.; Kumbhare, D.A. Re-Examining Myofascial Pain Syndrome: Toward Biomarker Development and Mechanism-Based Diagnostic Criteria. Curr. Rheumatol. Rep. 2021, 23, 69. [CrossRef] [PubMed]

22. Shah, J.P.; Thaker, N.; Heimur, J.; Aredo, J.V.; Sikdar, S.; Gerber, L. Myofascial Trigger Points Then and Now: A Historical and Scientific Perspective. PMR 2015, 7, 746-761. [CrossRef] [PubMed]

23. Zhang, H.; Lu, J.J.; Huang, Q.M.; Liu, L.; Liu, Q.G.; Eric, O.A. Histopathological nature of myofascial trigger points at different stages of recovery from injury in a rat model. Acupunct. Med. 2017, 35, 445-451. [CrossRef] [PubMed]

24. Hong, C.-Z. Considerations and recommendations regarding myofascial trigger point injection. J. Musculoskelet. Pain 1994, 2, $29-59$. [CrossRef]

25. Hong, C.Z.; Simons, D.G. Pathophysiologic and electrophysiologic mechanisms of myofascial trigger points. Arch. Phys. Med. Rehabil. 1998, 79, 863-872. [CrossRef]

26. Meng, F.; Ge, H.Y.; Wang, Y.H.; Yue, S.W. Myelinated Afferents Are Involved in Pathology of the Spontaneous Electrical Activity and Mechanical Hyperalgesia of Myofascial Trigger Spots in Rats. Evid. Based Complement. Altern. Med. 2015, $2015,404971$. [CrossRef]

27. Liu, Q.G.; Huang, Q.M.; Liu, L.; Nguyen, T.T. Structural and functional abnormalities of motor endplates in rat skeletal model of myofascial trigger spots. Neurosci. Lett. 2019, 711, 134417. [CrossRef]

28. Lewis, J.; Tehan, P. A blinded pilot study investigating the use of diagnostic ultrasound for detecting active myofascial trigger points. Pain 1999, 79, 39-44. [CrossRef]

29. Meuwly, J.Y.; Thiran, J.P.; Gudinchet, F. Application of adaptive image processing technique to real-time spatial compound ultrasound imaging improves image quality. Investig. Radiol. 2003, 38, 257-262. [CrossRef]

30. Shung, K.K. Diagnostic ultrasound: Past, present, and future. J. Med. Biol. Eng. 2011, 31, 371-374. [CrossRef]

31. Cruz-Montecinos, C.; Cerda, M.; Becerra, P.; Tapia, C.; Nunez-Cortes, R.; Latorre-Garcia, R.; Freitas, S.R.; Cuesta-Vargas, A. Qualitative ultrasonography scale of the intensity of local twitch response during dry needling and its association with modified joint range of motion: A cross-sectional study. BMC Musculoskelet. Disord. 2021, 22, 790. [CrossRef] [PubMed]

32. Donnelly, J. Travell, Simons E Simons' Myofascial Pain and Dysfunction: The Trigger Point Manual; Lippincott Williams \& Wilkins: Philadelphia, PA, USA, 2018.

33. Kuan, T.-S.; Hong, C.-Z.; Chen, S.-M.; Tsai, C.-T.; Yen, W.-C.; Chen, J.-T.; Feng, C.-Y. Myofascial pain syndrome: Correlation between the irritability of trigger points and the prevalence of local twitch responses during trigger point injection. J. Musculoskelet. Pain 2012, 20, 250-256. [CrossRef]

34. Serafin-Król, M.; Maliborski, A. Diagnostic errors in musculoskeletal ultrasound imaging and how to avoid them. J. Ultrason. 2017, 17, 188. [CrossRef]

35. Chou, L.-W.; Kao, M.-J.; Lin, J.-G. Probable mechanisms of needling therapies for myofascial pain control. Evid. Based Complement. Altern. Med. 2012, 2012, 705327. [CrossRef] [PubMed]

36. Chou, L.-W.; Hsieh, Y.-L.; Kuan, T.-S.; Hong, C.-Z. Needling therapy for myofascial pain: Recommended technique with multiple rapid needle insertion. BioMedicine 2014, 4, 13. [CrossRef] [PubMed]

37. Shah, J.P.; Gilliams, E.A. Uncovering the biochemical milieu of myofascial trigger points using in vivo microdialysis: An application of muscle pain concepts to myofascial pain syndrome. J. Bodyw. Mov. Ther. 2008, 12, 371-384. [CrossRef] [PubMed]

38. Hong, C.-Z.; Chen, J.-T.; Chen, S.-M.; Kuan, T.-S. Sensitive loci in a myofascial trigger point region are related to sensory nerve fibers. Am. J. Phys. Med. Rehabil. 1997, 76, 172. [CrossRef] 